\title{
Inhibition of Tyrosine 3-Monooxygenase/ Tryptophan 5-Monooxygenase Activation Protein Zeta (YWHAZ) Overcomes Drug Resistance and Tumorigenicity in Ovarian Cancer
}

\author{
Lan Hong $^{\mathrm{a}}$ Wangsheng Chen ${ }^{\mathrm{b}}$ Aiwen Xing ${ }^{\mathrm{a}} \quad$ Dongcai Wu ${ }^{\mathrm{c}}$ Shengtan Wang ${ }^{\mathrm{a}}$ \\ aDepartment of Gynecology, Hainan General Hospital, Haikou, 'Department of Radiology, Hainan \\ General Hospital, Haikou, 'Department of Obstetrics, Hainan General Hospital, Haikou, China
}

\section{Key Words}

Ovarian cancer $\cdot$ Tyrosine 3-monooxygenase/tryptophan 5-monooxygenase activation protein zeta $(\mathrm{YWHAZ}) \cdot$ Tumorigenicity • Resistance $・$ Cisplatin $•$ Paclitaxel

\begin{abstract}
Background/Aims: Cancer stem-like cells are the main cause of tumor occurrence, progression, and therapeutic resistance. However, the precise signals required for the maintenance of the stem-like traits of these cells in ovarian cancer remain elusive. We have thus worked to elucidate the functional role of Tyrosine 3-monooxygenase/tryptophan 5-monooxygenase activation protein zeta (YWHAZ), a gene encoding the 14-3-3Z protein, in the regulation of multidrug resistance and stem cell-like traits in ovarian cancer. Methods: We detected the YWHAZ levels in human ovarian cancer specimens and cell lines using quantitative reverse transcription-polymerase chain reaction (qRT-PCR) and western blots. MTS assays, soft agar colony formation assays, migration assays, cell cycle analysis, sphere formation assays, and flow cytometry were applied to investigate the functional role of YWHAZ in ovarian cancer. Results: Our data reveals substantially increased YWHAZ expression in both cisplatin- and paclitaxel-resistant ovarian cancer cells. Silencing YWHAZ restored the sensitivity of resistant ovarian cancer cells to cisplatin and paclitaxel. Furthermore, in vitro studies showed that down-regulation of YWHAZ inhibited cell cycle progression, migration, and the expression of stem cell markers. Moreover, tumorigenicity was suppressed in tumor-bearing BALB/c nude mice following YWHAZ knockdown. Additionally, we demonstrated that the expression of YWHAZ was directly down-regulated by miR-30e in resistant ovarian cancer cells. Conclusion: Our results have led to new insights into the essential role of YWHAZ in the regulation of tumourigenesis, stem-like traits, and drug resistance in ovarian cancer, thereby helping to identify a potential target for ovarian cancer therapy.

(C) 2018 The Author(s)

Published by S. Karger AG, Basel

Wangsheng Chen

Department of Radiology, Hainan General Hospital

No.19, Xiuhua Road, Xiuying District, Haikou 570311, Hainan Province (China)

E-Mail wangshengchen15@163.com
\end{abstract}

KARGER 


\section{Cellular Physiology Cell Physiol Biochem 2018;49:53-64 and Biochemistry Published online:22 August, 2018 \begin{tabular}{l|l} 
DO 2018 The Author(s). Published by S. Karger AG, Basel \\
www.karger.com/cpb
\end{tabular}}

Hong et al.: Role of YWHAZ in Ovarian Cancer

\section{Introduction}

Ovarian cancer is the second major cause of gynecologic cancer-associated death in the world [1,2]. There are nearly 240, 000 new cases annually in the world, accounting for about $4 \%$ of women's cancers, and about 152, 000 women die from this disease each year [3-5]. This high mortality rate is due in part to the fact that most new cases of ovarian cancer are detected at advanced stages. Although cancer patients often initially respond to postoperative adjuvant platinum and taxane chemotherapy, most of them relapse within 12-24 months and gradually die of chemotherapeutic drug resistance [6-9]. The standard chemotherapy procedure for ovarian cancer is usually accompanied by chemical resistance, which is a major obstacle to a lasting cure [10-12]. Selective pressure-induced random mutations, continuous genetic alterations, and cancer cell stem cell-like properties are the main causes of chemotherapy-resistant cells during chemotherapy [13]. The identification of molecular biomarkers of drug sensitivity and drug resistance is critical for effective prognosis. A recent study on whole-genome characterization of chemotherapeutic-resistant ovarian cancer showed that 62 genes are simultaneously altered in cisplatin-, doxorubicin-, and paclitaxel-resistance phenotypes [14]. Acquired chemotherapy resistance is mainly associated with the inactivation of tumor suppressors, loss of BRCA1 promoter methylation, and overexpression of the drug efflux pump MDR1 [15]. However, little is known about the underlying mechanisms that contribute to both cisplatin- and paclitaxel-resistance of ovarian cancer under the selective pressure of chemotherapy.

In this study, we explored the candidate genes that could confer both cisplatin- and paclitaxel-resistance in ovarian cancer cells. Using genomic analysis, we found that YWHAZ gene expression was considerably increased in both cisplatin- and paclitaxel-resistant cells. Moreover, YWHAZ silencing restored the sensitivity of resistant ovarian cancer cells to cisplatin and paclitaxel. YWHAZ silencing inhibited cell cycle progression, migration, and the development of stem cell-like qualities, and it reduced the tumorigenicity of resistant ovarian cancer cells. These findings suggest that YWHAZ may be a potential therapeutic target for ovarian cancer treatment and for overcoming cisplatin- and paclitaxel-resistance.

\section{Materials and Methods}

\section{Cell lines and cell culture}

The human epithelial serous ovarian cancer cell line OV2008 (cisplatin-sensitive) was purchased from ECACC (UK). Cells were maintained in Roswell Park Memorial Institute (RPMI) 1640 medium containing $10 \%$ fetal bovine serum (FBS) and $1 \%$ penicillin/streptomycin (Thermo Fisher Scientific, USA) at $37^{\circ} \mathrm{C}$ in a humidified atmosphere of $5 \% \mathrm{CO}_{2}$. Cisplatin and paclitaxel (Sigma-Aldrich) were dissolved in dimethyl sulfoxide (DMSO). Cells resistant to cisplatin and paclitaxel were obtained from the parental cell line 0V2008 by gradually increasing doses of cisplatin or paclitaxel in cell culture medium during cell passaging for about 6 months. According to the ECACC guidelines, CP70 (cisplatin-resistant) and SKOV3/PTX (paclitaxelresistant) cells were cultured for $72 \mathrm{~h}$ in cultured medium containing $1 \mu \mathrm{g} / \mathrm{ml}$ cisplatin or paclitaxel for each passage.

\section{Transfection and infection}

EsiRNA transfection was performed using Lipofectamine 2000 (Invitrogen, USA). For stable knockdown of YWHAZ, a short hairpin RNA (shRNA) targeting YWHAZ was synthesized and cloned into the lentiviral vector (Genechem, Shanghai, China). The lentiviral vector carrying a scrambled shRNA served as negative control (shScramble). The lentiviral vectors were co-transfected with pHelper1 and pHelper2 vectors into 293T cells using Lipofectamine 2000. Viral supernatants were collected $48 \mathrm{~h}$ after transfections, cleared through a $0.45 \mu \mathrm{m}$ filter, and ultra-centrifuged. Ovarian cancer cells were infected with lentiviral particles for $48 \mathrm{~h}$ for YWHAZ knockdown, and stable YWHAZ knockdown cells were obtained under puromycin selection. 


\section{Cellular Physiology Cell Physiol Biochem 2018;49:53-64 \begin{tabular}{l|l|l} 
and Biochemistry & Published online: 22 August, 2018 & $\begin{array}{l}\text { C 2018 The Author(s). Published by S. Karger AG, Basel } \\
\text { www.karger.com/cpb }\end{array}$ \\
\hline
\end{tabular}}

Hong et al.: Role of YWHAZ in Ovarian Cancer

\section{Real-time quantitative reverse transcription PCR (qRT-PCR)}

Total RNA was isolated from cells using Trizol reagent (Invitrogen, USA) and was used as a template to make cDNA using a cDNA Reverse Transcription Kit (Invitrogen, USA). qPCR amplification conditions were as follows: $95^{\circ} \mathrm{C}$ for $10 \mathrm{~min}, 94^{\circ} \mathrm{C}$ for $30 \mathrm{~s}, 55^{\circ} \mathrm{C}$ for $15 \mathrm{~s}$, and $72^{\circ} \mathrm{C}$ for $55 \mathrm{~s}$ for 35 cycles in Real-Time PCR Instrument (Applied Biosystems, USA). The primer sequences were as follows: YWHAZ, 5'-GCTGGTGATGACCAAGAAAGG-3' and 5'-GGATGTGTTGGTTGCATTTCCT-3'; GAPDH, 5'-GCCACTCGAATAGTGCAACC-3' and 5'-ACCACCTCTCAGGTGGTGTA-3'. Relative mRNA expression levels were calculated using the formula $2^{\text {-(CtYWHAZ-CtGAPDH). }}$

MTS assay

Cells $\left(3 \times 10^{3}\right)$ were seeded in 96 -well plates and cultured at $37^{\circ} \mathrm{C}$. At the indicated time points, cells were measured with MTS by the manufacturer's instructions (Promega Corp., Madison, WI). The absorbance values were measured at $492 \mathrm{~nm}$ in an automatic microplate reader. Each assay was performed three times.

\section{Soft agar colony formation assay}

Single cells (500) were seeded in the top agar layer in each well of a 24 -well culture plate with a $0.3 \%$ top agar layer and a $0.4 \%$ bottom agar layer (SeaPlaque Agarose, Cambrex, USA). Cells were cultured at $37^{\circ} \mathrm{C}$ for 3 weeks. Colonies were then stained with crystal violet $(0.01 \%$ in $10 \% \mathrm{MetOH})$ and counted under a microscope.

\section{Migration assay}

Cells $\left(1 \times 10^{6}\right)$ in medium without FBS were seeded into the upper chamber (Millipore, Billerica, MA), while medium containing $10 \%$ FBS was added to the lower chamber. After incubation at $37^{\circ} \mathrm{C}$ for $24 \mathrm{~h}$, cells were ethanol-fixed and Giemsa-stained (Sigma, St. Louis, MO, USA). The migrated cells were counted under an inverted microscope.

\section{Cell cycle analysis}

Following transfection, cells were collected and washed with phosphate-buffered saline (PBS). Cell pellets were fixed in $70 \%$ ethanol overnight at $-20^{\circ} \mathrm{C}$. The fixed cells were re-suspended in PBS containing $10 \mathrm{mg} / \mathrm{mL}$ RNase $\mathrm{A}$, incubated for $1 \mathrm{~h}$ at $37^{\circ} \mathrm{C}$, and stained by adding $50 \mathrm{mg} / \mathrm{mL}$ PI for $30 \mathrm{~min}$ at room temperature in the dark. DNA contents of the stained cells were analyzed using Cell Quest Software with a FACSCalibur flow cytometry instrument (Becton Dickinson, Bedford, MA).

\section{Luciferase reporter assay}

To construct the firefly luciferase reporters, the 3'-UTR and 3'-UTR mutant of YWHAZ were amplified by PCR and inserted into the pGL3-control vector (Promega) at the Xba1 site immediately downstream of the stop codon of firefly luciferase. Cells were co-transfected with a firefly luciferase reporter vector and a Renilla luciferase control vector (pRL-CMV), with or without miRNA mimics, using Lipofectamine 2000 in 24-well plates. Luciferase activities were measured $24 \mathrm{~h}$ after transfection using a dual-luciferase reporter assay system (Promega) in which firefly luciferase activity was normalized to Renilla luciferase activity.

\section{Sphere formation assays}

We performed sphere formation assays to investigate the impact of YWHAZ on cancer stem cells. Cells $\left(1 \times 10^{4}\right)$ were seeded in ultra-low attachment 6-well plates (Corning Inc., Corning, NY, USA) containing serum-free Dulbecco's modified Eagle's medium (DMEM)/F-12 (1:1 ratio) media with 1\% penicillinstreptomycin, B27 and N2 supplements (Gibco), $20 \mathrm{ng} / \mathrm{ml} \mathrm{rhEGF,} \mathrm{and} 20 \mathrm{ng} / \mathrm{ml}$ fibroblast growth factor (Invitrogen, USA). After seeding, cells were observed to ensure that spheres were forming as a result of cell multiplication and not due to adherence of nearby cells. Spheres $(>50 \mu \mathrm{m})$ were imaged and counted.

\section{Western blotting}

Proteins were electrophoresed on a $10 \%$ sodium dodecyl sulfate-polyacrylamide gel electrophoresis (SDS-PAGE) gel and transferred onto a polyvinylidene difluoride (PVDF) membrane. After blocking with $5 \%$ bovine serum albumin for $1 \mathrm{~h}$, the membrane was incubated with primary antibody at $4^{\circ} \mathrm{C}$ overnight. The membrane was washed with Tris-buffered saline and Tween 20 (TBST), and the membrane was then 


\section{Cellular Physiology Cell Physiol Biochem 2018;49:53-64 and Biochemistry Published on/ine:22 August, $2018 \begin{aligned} & \text { D } 2018 \text { The Author(s). Published by S. Karger AG, Basel } \\ & \text { www.karger.com/cpb }\end{aligned}$}

Hong et al.: Role of YWHAZ in Ovarian Cancer

incubated with the horseradish peroxidase (HRP)-conjugated secondary antibody at room temperature for $1 \mathrm{~h}$. After washing with TBST, proteins were detected using ECL PlusWestern Blotting Detection Reagents (GE Healthcare Life Sciences, Piscataway, NJ, USA). The gray value was analyzed using ImageJ software.

Flow cytometry

We used the ALDEFLUOR kit (StemCell Technologies, Durham, NC) to isolate a subpopulation with high aldehyde dehydrogenase (ALDH) enzymatic activity. For each sample, a specific ALDH inhibitor, diethylaminobenzaldehyde (DEAB), was used as a negative control. Anti-human PE-CD133 antibody was purchased from Miltenyi Biotec (Auburn, CA). We analyzed $\mathrm{ALDH}^{+} / \mathrm{CD} 133^{+}$and $\mathrm{ALDH}^{-} / \mathrm{CD} 133^{-}$ subpopulations using a Flow Cytometer.

\section{Animal experiments}

CP70 and SKOV3/PTX cells stably transfected with shRNA were validated and re-suspended in PBS. Cells were injected subcutaneously into the right and left flank of female BALB/c nude mice $\left(5 \times 10^{6}\right.$ cells each). Each week, we measured the (a) length and (b) width of tumors with a Vernier caliper, and tumor volumes $(\mathrm{V})$ were calculated using the formula $\mathrm{V}=\mathrm{ab}^{2} / 2$. We evaluated the statistical significance of tumor size differences in the shYWHAZ and shScramble control transfected groups by Student's t-test. The study was approved by the Animal Ethics Committee of Hainan General Hospital, China. All animal experiments followed relevant guidelines and regulations.

\section{Immunohistochemistry (IHC)}

The experiments were approved by the Ethical Review Committees of Human Research Subjects of Hainan General Hospital. A total of 84 ovarian cancer patients were enrolled in this study from Hainan General Hospital from January 2011 to December 2012. All study subjects approved and signed the informed consent form, and we collected tumor tissue samples from each subject. Samples of tumor tissues or consented xenograft mouse tissues from CP70- and SKOV3/PTX-transfected cells were paraffin embedded and cut into $5 \mu \mathrm{m}$ sections. We placed sections on slides coated with polylysine, which we then deparaffinized in xylene and rehydrated with graded alcohol. Antigen retrieval was performed with heated citrate buffer (pH 6; Dako). After blocking with 10\% goat serum, samples were either incubated with primary antibody [rabbit anti-YWHAZ (1:100)] or a negative control [an isotype IgG (Sigma)] at $4^{\circ} \mathrm{C}$ overnight in a humidified container. According to the manufacturer's instruction, we performed IHC with the Dako Envision Plus system (Dako, Carpinteria, CA, USA). We evaluated the intensity of staining by digital image analysis, and scores from 0 to 4 were used to define the percentage of positive tumors ( 0 for low expression or negative control, 1 for $0-10 \%, 2$ for $10-25 \%, 3$ for $25-50 \%$, and 4 for high expression of $>50 \%$ ).

\section{Statistical analysis}

All data represent the mean \pm standard error (S.E.M.) from at least three independent experiments. We assessed statistical significance by two-tailed Student's $t$-test or one-way multivariate analysis of variance (ANOVA) using SPSS 22.0 statistical software (SPSS, Inc., Chicago, IL, USA). We analyzed the survival rate using the Kaplan-Meier method. A $P$ value of less than 0.05 was considered to be statistically significant.

\section{Results}

Upregulation of YWHAZ in cisplatin and paclitaxel-resistant ovarian cancer cells

To determine the key factor associated with cisplatin- and paclitaxel-resistance in ovarian cancer, differences in gene expression levels were compared between chemosensitive cells (OV2008) and chemotherapy-resistant cells (CP70 and SKOV3/PTX). The data from qRT-PCR and western blotting showed that YWHAZ was significantly upregulated in both CP70 and SKOV3/PTX cells (Fig. 1A, B). The rate of positive YWHAZ protein expression was significantly higher in ovarian cancer samples than in normal ovarian tissues (Fig. 1C). Moreover, high YWHAZ expression was significantly associated with poor overall survival $(P$ $=0.025$ ) and poor progression-free survival of ovarian cancer patients $(P=0.003$, Fig. 1D). These findings suggest that YWHAZ may play an important role in the regulation of both 
cisplatin- and paclitaxelresistance in ovarian cancer cells.

$\begin{array}{lr}\text { YWHAZ } & \text { knockdown } \\ \text { inhibited } & \text { the }\end{array}$
progression of cell cycle in resistant ovarian cancer cells

Cell cycle progression is critical in chemotherapy drug resistance. To find the molecular mechanism of YWHAZ in cisplatinand paclitaxel-resistance in ovarian cancer cells, we analyzed the effect of YWHAZ knockdown on cell cycle distribution. We performed qRT-PCR to examine the efficiency of YWHAZ knockdown in both cisplatin- and paclitaxelresistant ovarian cancer cells after YWHAZ esiRNA (esiYWHAZ) transfection (Fig. 2A, $P<0.05$ ). Flow cytometry analysis revealed that YWHAZ knockdown increased the cell population in G0/G1 phase but decreased the cell population in $\mathrm{S}$ phase in both cisplatin- and

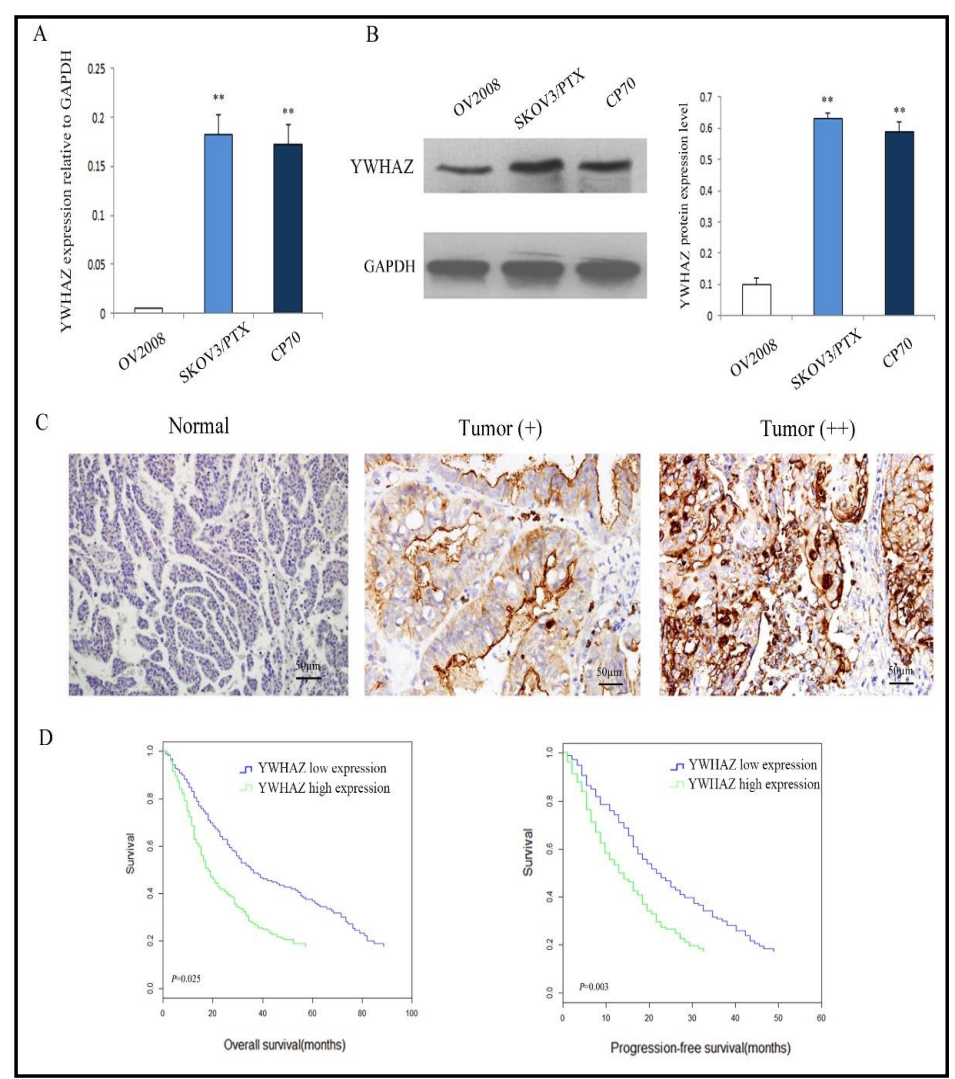

Fig. 1. Upregulation of YWHAZ in cisplatin and paclitaxel-resistant ovarian cancer cells. The expression of YWHAZ in cisplatin- and paclitaxel-resistant ovarian cancer cells was measured using (A) qRT-PCR and (B) western blotting. C: YWHAZ expression in ovarian cancer tissue samples detected by IHC. D: High YWHAZ expression was significantly associated with poor overall survival and progression-free survival in ovarian cancer patients.

\section{paclitaxel-resistant ovarian} cancer cells (Fig. 2B, $P<0.05$ ). These data indicate that YWHAZ knockdown inhibits cell cycle progression in resistant ovarian cancer cells.

YWHAZ knockdown inhibited cell growth, migration, and drug resistance of resistant ovarian cancer cells

Next, we studied the effects of YWHAZ silencing on cell growth, migration, and drug resistance of resistant ovarian cancer cells. Cell growth of both cisplatin- and paclitaxelresistant ovarian cancer cells was reduced significantly after YWHAZ silencing (Fig. 3A). A Transwell migration assay showed that the migration abilities of both cisplatin- and paclitaxel-resistant ovarian cancer cells were suppressed dramatically following YWHAZ knockdown (Fig. 3B). Moreover, the sensitivity of resistant ovarian cancer cells to cisplatin and paclitaxel significantly increased following YWHAZ knockdown (Fig. 3C). Taken together, these findings suggest that YWHAZ knockdown inhibits cell growth, migration, and drug resistance of resistant ovarian cancer cells.

YWHAZ knockdown inhibited colony formation and stem cell-like traits in resistant ovarian cancer cells

A soft agar colony forming assay revealed that the colony forming abilities of both cisplatin- and paclitaxel-resistant ovarian cancer cells were noticeably inhibited by YWHAZ 
Fig. 2. YWHAZ knockdown inhibited the cell cycle progression in resistant ovarian cancer cells. A: The expression of YWHAZ was significantly knocked down following YWHAZ esiRNA transfection in both CP70 and SKOV3/PTX cells, which was detected by qRT-PCR. ${ }^{*} \mathrm{P}<0.05$ (t-test). B: YWHAZ knockdown significantly increased cell population in G0/G1 phase but decreased cell population in $S$ phase in both CP70 and SKOV3/PTX cells, which was detected by flow cytometry.

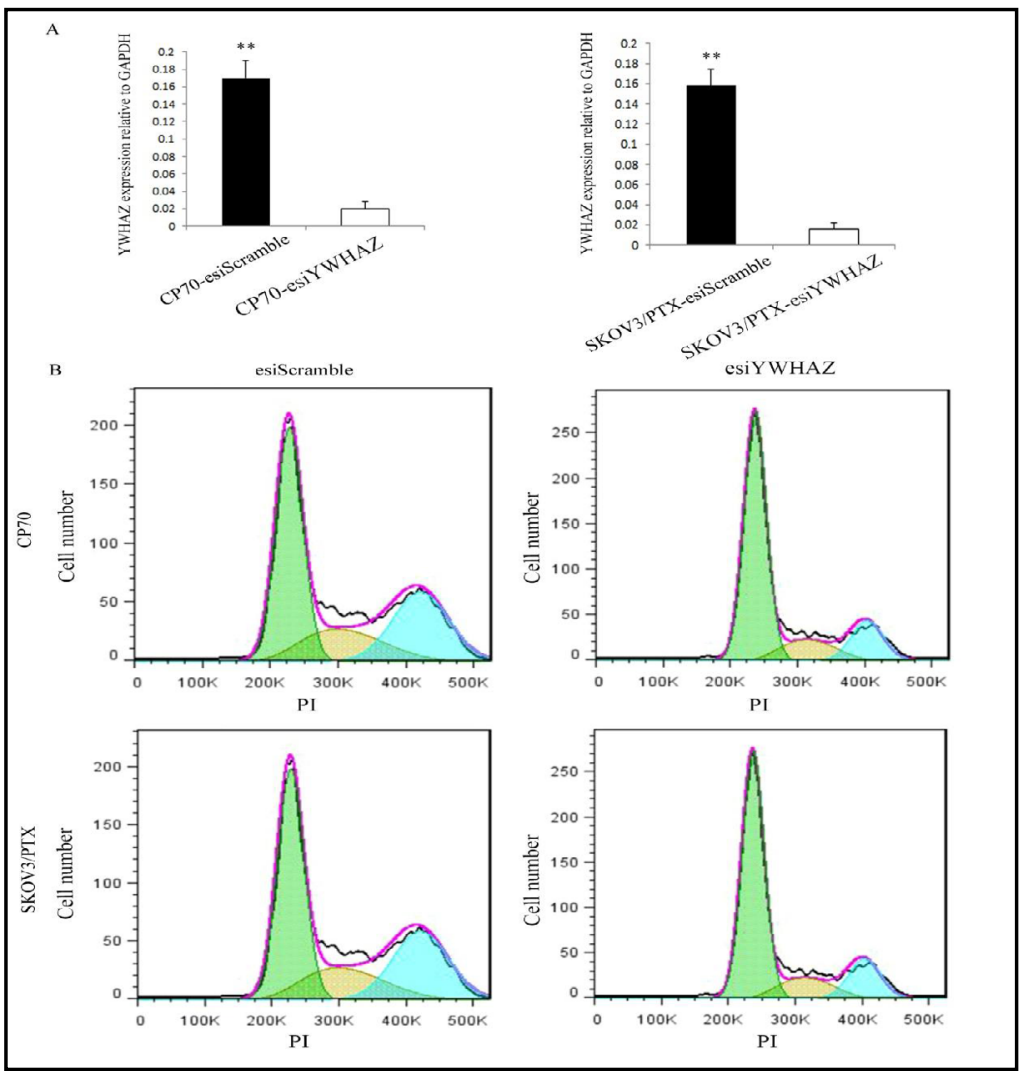

Fig. $\quad 3 . \quad$ YWHAZ knockdown inhibited cell growth, migration, and drug resistance of resistant ovarian cancer cells. A: Cell proliferation was significantly reduced after YWHAZ knockdown in both CP70 and SKOV3/ PTX cells, as detected by MTS assay. B: Cell migration rates of both cisplatin- and paclitaxelresistant ovarian cancer cells were reduced dramatically after YWHAZ silencing, which was measured using a Transwell migration assay. C: Drug sensitivity of resistant ovarian cancer cells to cisplatin and paclitaxel increased after YWHAZ silencing, which was detected by MTS assay. ${ }^{*} \mathrm{P}<0.05$ (t-test).

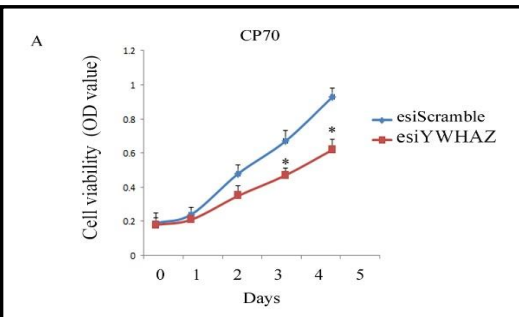

B
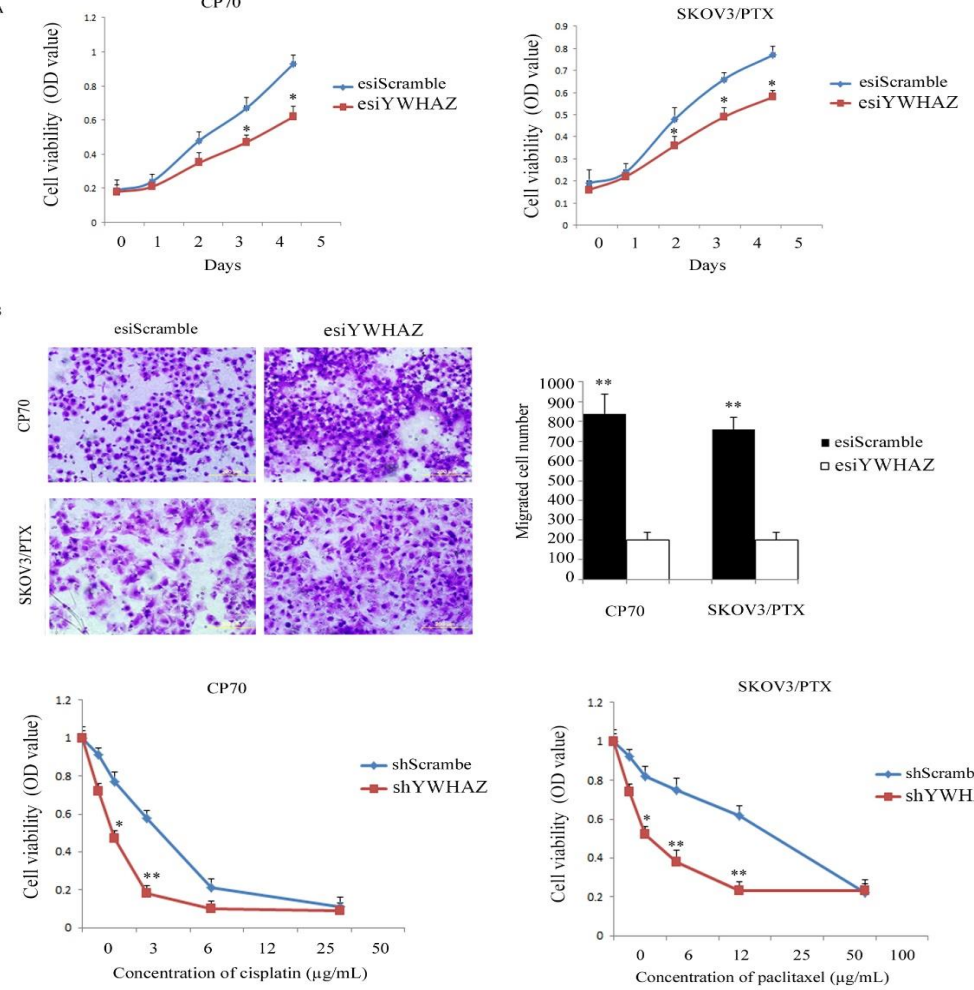


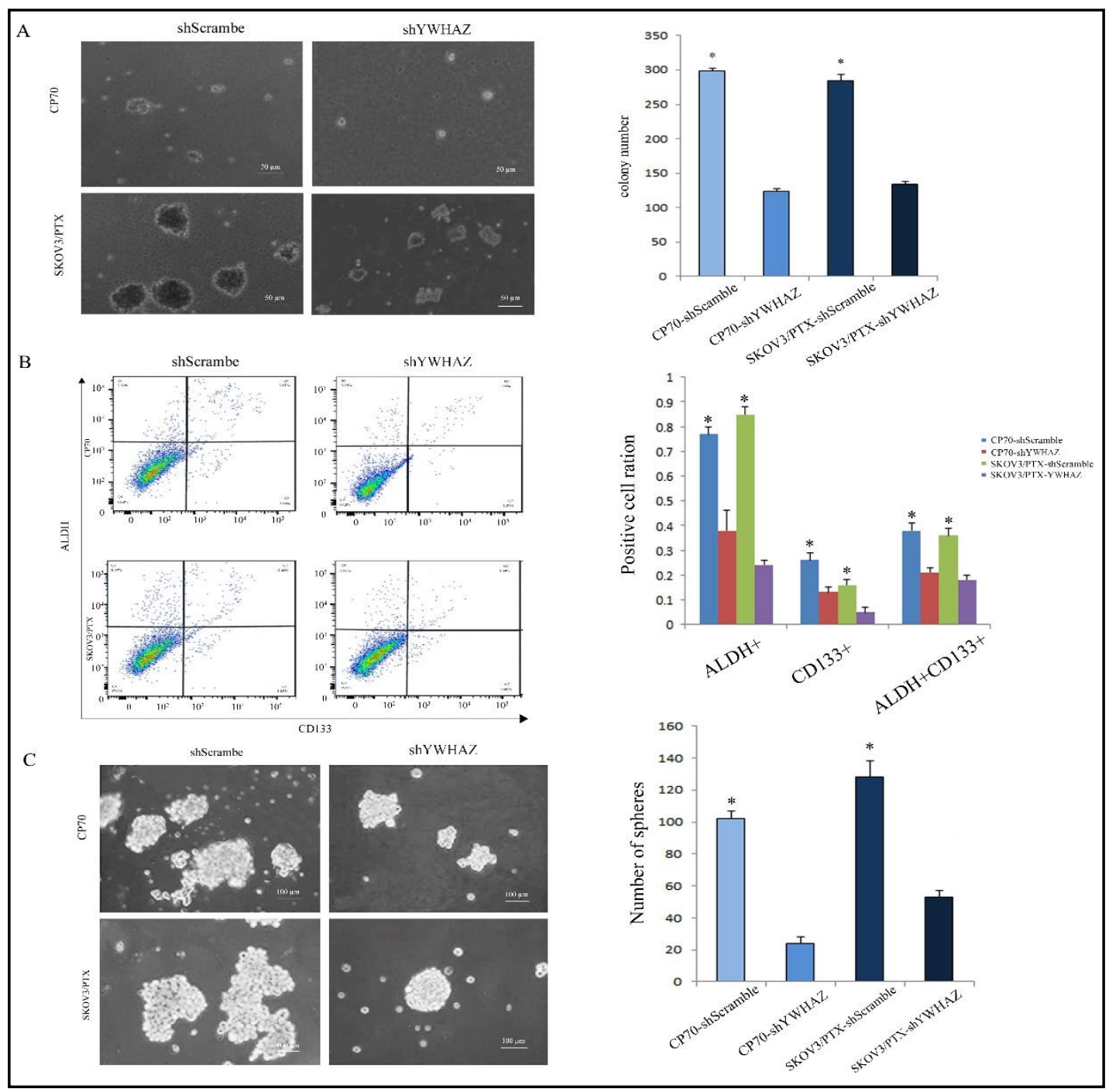

Fig. 4. YWHAZ knockdown inhibited colony formation and stem cell-like properties in resistant ovarian cancer cells. A: Cellular anchorage-independent growth was significantly inhibited in cisplatin- and paclitaxel-resistant ovarian cancer cells after stable silencing of YWHAZ, which was detected by a soft agar assay. $\mathrm{B}: \mathrm{ALDH}^{+}, \mathrm{CD}_{133^{+}}$, and $\mathrm{ALDH}^{+} / \mathrm{CD} 133^{+}$cell populations were significantly decreased after YWHAZ knockdown, which was measured by flow cytometry. C: Tumor sphere-forming ability of both resistant ovarian cancer cells was significantly inhibited after stable silencing of YWHAZ, which was detected using a sphere formation assay. ${ }^{*} \mathrm{P}<0.05$ (t-test).

knockdown. This result serves as evidence that the silencing of YWHAZ inhibited the cellular anchorage-independent growth of resistant ovarian cancer cells in vitro (Fig. 4A). Additional evidence suggested that cancer cell stem-like qualities are a major cause of cancer occurrence and drug resistance. CD133 and ALDH are used to define cancer stem cells in multiple cancers. Using these two markers and flow cytometric analysis, we found that stem cell-like populations were significantly decreased following YWHAZ knockdown (Fig. 4B, $P<0.05$ ). Consistently, the tumor sphere-forming abilities of both resistant ovarian cancer cell lines were significantly inhibited after YWHAZ silencing in the sphere formation assay (Fig. 4C, $P<0.05)$. These data suggest that YWHAZ knockdown inhibits colony formation and stem cell-like properties in resistant ovarian cancer cells. 


\section{Cellular Physiology Cell Physiol Biochem 2018;49:53-64 \begin{tabular}{l|l|l} 
and Biochemistry Published online: 22 August, 2018 & $\begin{array}{l}\text { @ } 2018 \text { The Author(s). Published by S. Karger AG, Basel } \\
\text { www.karger.com/cpb }\end{array}$ \\
\hline
\end{tabular}

miR-30e regulated the expression of YWHAZ in resistant ovarian cancer cells

We used a luciferase reporter assay to determine if YWHAZ was potentially regulated by miR-30e. To determine if the 3'-UTR of YWHAZ mRNA can be recognized directly by miR$30 \mathrm{e}$, we cloned a 3'-UTR sequence containing the predicted target site and a mutated 3'-UTR sequence into a pGL3 vector to produce the vectors pGL3-YWHAZ-wt and pGL3-YWHAZmut, respectively (Fig. 5A). miR-30e mimics or controls were co-transfected into HEK293 cells along with the produced vectors. The transfection efficiency was normalized with a Renilla luciferase vector (pRL-TK). Compared with the control group, luciferase activity was dramatically decreased in cells co-transfected with miR-30e mimics and the pGL3-YWHAZwt vector (Fig. 5B). The protein expression of YWHAZ was then detected in resistant ovarian cancer cells transfected with miR-30e mimics or controls. The results showed that miR-30e overexpression decreased YWHAZ expression in resistant ovarian cancer cells (Fig. 5C). These findings suggest that miR-30e regulates the expression of YWHAZ in resistant ovarian cancer cells.

Silencing of YWHAZ inhibits tumorigenicity of resistant OC cell in vivo

Using an in vivo mouse model, we further investigated the effect of YWHAZ silencing on the tumorigenicity of resistant ovarian cancer cells. Resistant ovarian cancer cells stably transfected with YWHAZ shRNA or with a shScramble control were subcutaneously injected into immunodeficient Balb/C mice. During the tumorigenic period, the tumor growth for both CP70 (Fig. 6A) and SKOV3/PTX (Fig. 6B) cells was slower in the shYWHAZ group than in the shScramble control group. Expression of YWHAZ was significantly decreased in tumor tissues of the shYWHAZ group than in those of the shScramble control group, indicated by IHC staining (Fig. 6C). These data illustrate that the silencing of YWHAZ inhibits tumorigenicity of resistant ovarian cancer cells in vivo.

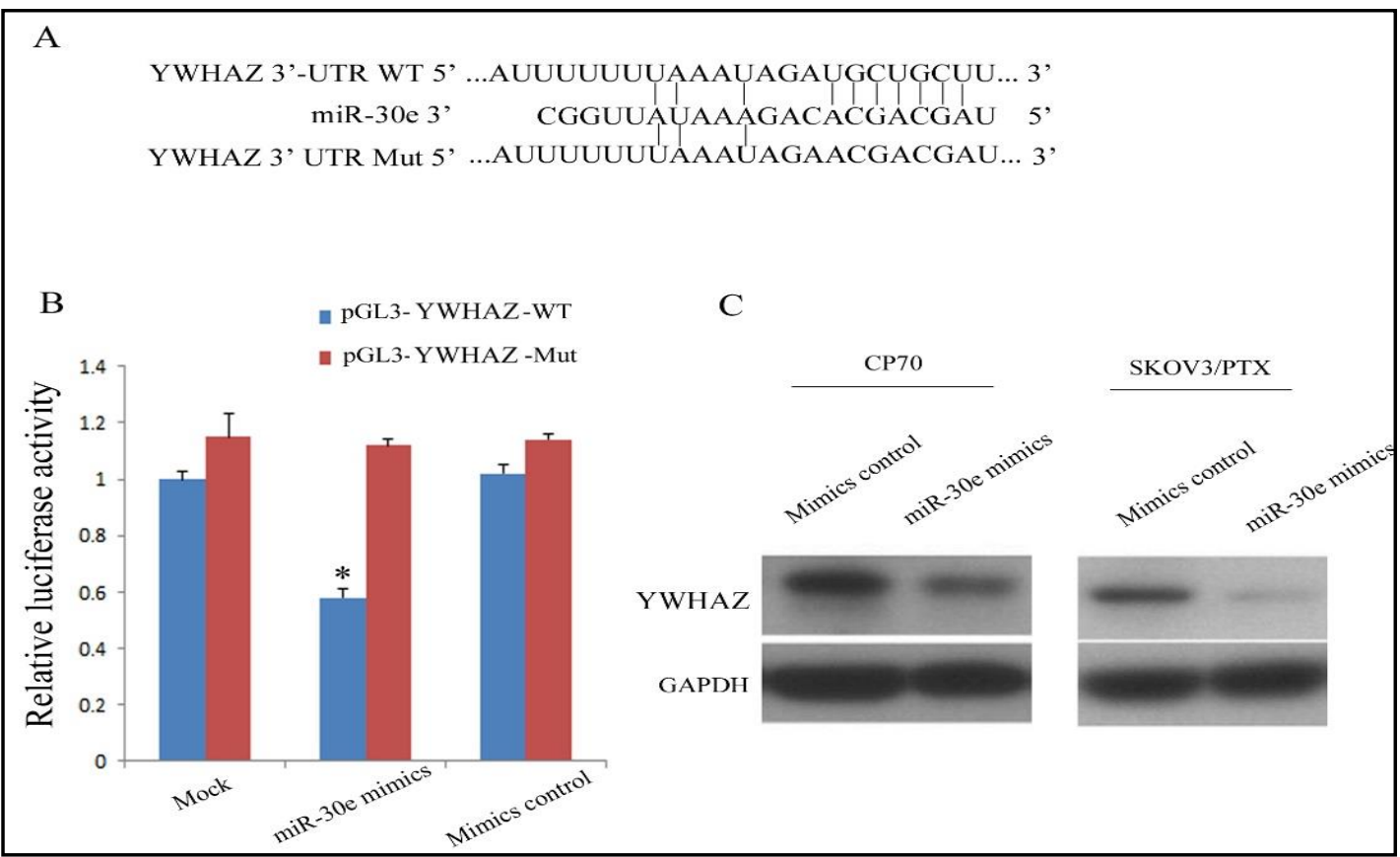

Fig. 5. miR-30e-regulated YWHAZ expression in resistant ovarian cancer cells. A: The predicted binding sites of YWHAZ mRNA 3'-UTR and miR-30e. B: Compared with the control group, luciferase activity was dramatically decreased in cells co-transfected with miR-30e mimics and pGL3-YWHAZ-wt. C: Overexpression of miR-30e decreased YWHAZ expression in resistant ovarian cancer cells, as was indicated by western blotting. 


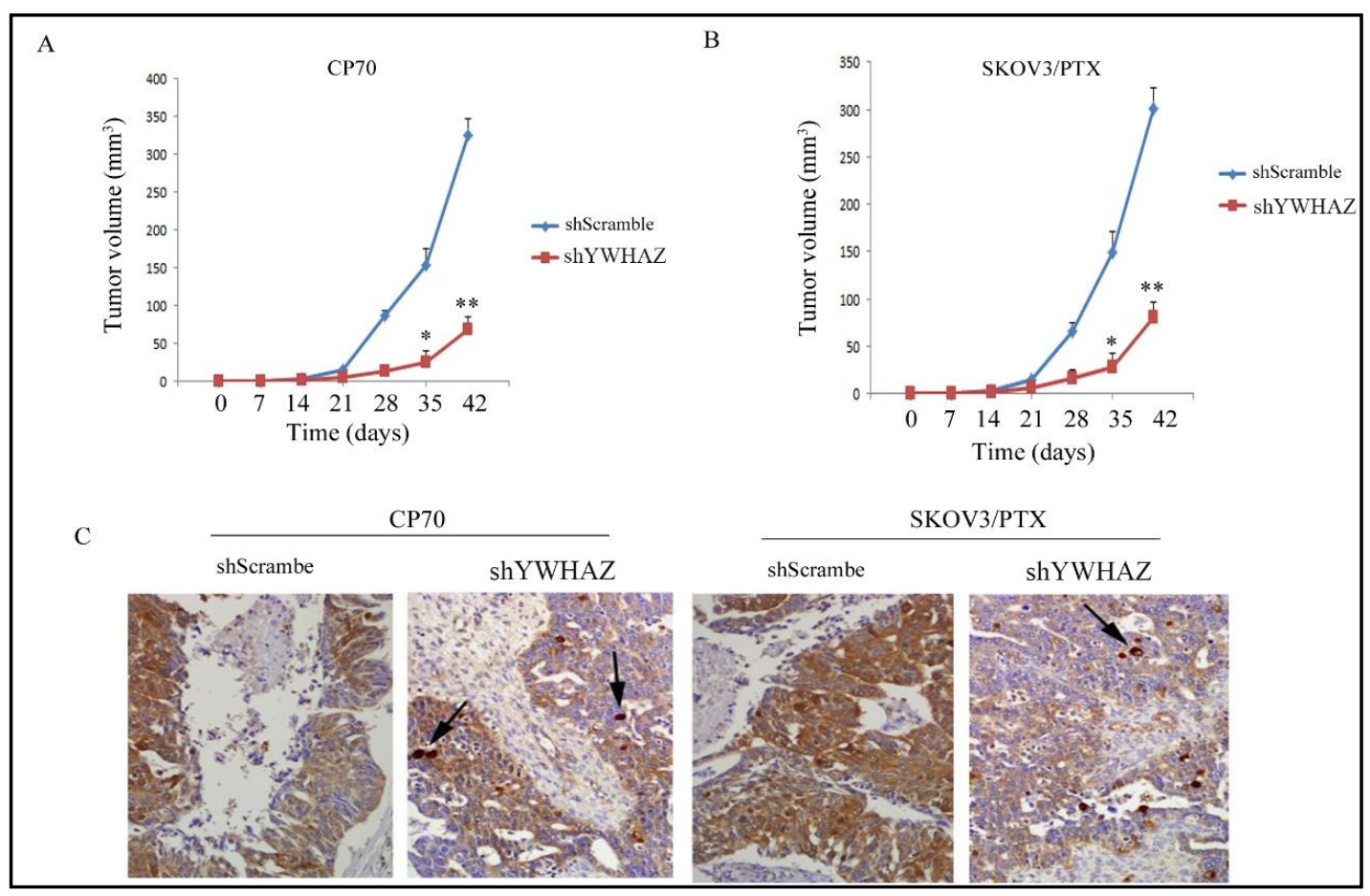

Fig. 6. YWHAZ knockdown inhibited tumorigenicity of resistant ovarian cancer cells in vivo. Tumor growth was significantly slower in shYWHAZ stably transfected (A) CP70 and (B) SKOV3/PTX cells than in those of shScramble transfected control cells, as we have shown via tumor images (left) and a tumor growth curve (right). ${ }^{*} \mathrm{P}<0.05$ (t-test). C: YWHAZ expression in tumor tissues was significantly decreased in the shYWHAZ stably transfected group when compared to those in the shScramble control transfected group, as we have indicated by IHC.

\section{Discussion}

YWHAZ is a member of the protein tyrosine phosphatase (PTP) family [16]. YWHAZ is involved in several cellular processes such as cell growth, differentiation, mitosis, and oncogenic transformation [17-19]. YWHAZ could serve as a promising prognostic biomarker in localized PCa to predict poor prognosis and to identify a subgroup of tumors [20]. YWHAZ silencing restored doxorubicin-based drug sensitivity in breast cancer cells [21]. These findings suggest that YWHAZ plays an important role in the development of cancer and chemotherapy resistance.

Chemotherapy based on platinum is currently the first-line treatment for HGSC patients with advanced-stage cancer $[22,23]$. Tumors resistant to platinum, however, are a key obstacle in clinical treatment [24]. Platinum-resistant ovarian cancer exists in the spectrum of heterogeneous and complex diseases [25]. The mechanisms of platinum resistance may include cisplatin transport and trafficking changes, apoptosis disruption, increased tolerance to cisplatin-DNA adducts, and increased DNA repair to cisplatin-DNA interactions [26]. Many phenotypes of ovarian cancer exhibit different resistance pathways simultaneously [27]. According to the free interval to platinum for less than or greater than 6 months, patients with recurrent ovarian cancer are categorized as either platinum resistant or platinum sensitive [28]. Some second-line chemotherapeutic drugs have been approved for the treatment of ovarian cancer such as paclitaxel, topotecan, etoposide, gemcitabine, and trabectedin [29]. If recurrence occurs within 6 months of the initial treatment, or if it occurs following complete clinical response to chemotherapy including platinum, liposomal paclitaxel can be used alone [30]. However, if recurrence happens after more than 6 months, liposomal paclitaxel

\section{KARGER}




\section{Cellular Physiology Cell Physiol Biochem 2018;49:53-64 \begin{tabular}{l|l|l} 
and Biochemistry & $\begin{array}{l}\text { DOI: 10.1159/000492839 } \\
\text { Published online: 22 August, } 2018\end{array}$ & $\begin{array}{l}\text { C) 2018 The Author(s). Published by S. Karger AG, Basel } \\
\text { www.karger.com/cpb }\end{array}$ \\
\hline
\end{tabular}}

Hong et al.: Role of YWHAZ in Ovarian Cancer

may be combined with platinum for treatment. Unfortunately, these second-line drugs have had poor outcomes in trials using large populations of unselected relapsed patients [28]. Hence, it is important to determine the factors involved in both cisplatin- and paclitaxelresistance in HGSC under the selective pressure of chemotherapy.

In this study, YWHAZ upregulation was found to promote drug resistance to both cisplatin and paclitaxel. Recent studies have shown that activating YWHAZ mutations promotes the proliferation and migration of cholangiocarcinoma cells and is related to tumor relapse [24, 25]. Moreover, transfection of YWHAZ in cell lines increased cell proliferation, colony formation, and migration [31]. Our study found that miR-30e can regulate YWHAZ in resistant ovarian cancer cells. Therefore, the miR-30e/YWHAZ signaling pathway may take part in both cisplatin- and paclitaxel-resistance of HGSC under the selective pressure of chemotherapy.

It has been reported that YWHAZ is an oncogene in gastric cancer, colon cancer, and breast cancer [18, 21, 32]. YWHAZ, however, can inhibit the proliferation and migration of lung cancer cells by promoting the endocytic EGFR degradation, which suggests that YWHAZ can to be a tumor suppressor in lung cancer [33]. In this study, YWHAZ expression increased in about one-third of clinical ovarian cancer tissue samples, whereas it could not be detected in normal ovarian tissue samples. Furthermore, high YWHAZ expression significantly correlated with poor overall survival in ovarian cancer patients. YWHAZ silencing inhibited proliferation, cell cycle progression, migration, drug resistance, stemness, and tumorigenicity of resistant ovarian cancer cells. These data suggest that YWHAZ can promote drug resistance and stem cell-like traits, and that YWHAZ may be a potential therapeutic target for ovarian cancer.

\section{Acknowledgements}

This study was supported by the Hainan Natural Science Foundation-funded project (ZDXD 2015069, 813209).

\section{Disclosure Statement}

No conflict of interests exists.

\section{References}

1 Winterhoff B, Freyer L, Hammond E, Giri S, Mondal S, Roy D, Teoman A, Mullany SA, Hoffmann R, von Bismarck A, Chien J, Block MS, Millward M, Bampton D, Dredge K, Shridhar V: PG545 enhances anti-cancer activity of chemotherapy in ovarian models and increases surrogate biomarkers such as VEGF in preclinical and clinical plasma samples. Eur J Cancer 2015;51:879-892.

$>2$ Worku T, Bhattarai D, Ayers D, Wang K, Wang C, Rehman ZU, Talpur HS, Yang L: Long Non-Coding RNAs: the New Horizon of Gene Regulation in Ovarian Cancer. Cell Physiol Biochem 2017;44:948-966.

-3 Sallinen H, Heikura T, Koponen J, Kosma VM, Heinonen S, Yla-Herttuala S, Anttila M: Serum angiopoietin-2 and soluble VEGFR-2 levels predict malignancy of ovarian neoplasm and poor prognosis in epithelial ovarian cancer. BMC Cancer 2014;14:696.

-4 Han X, Zhen S, Ye Z, Lu J, Wang L, Li P, Li J, Zheng X, Li H, Chen W, Li X, Zhao L: A Feedback Loop Between miR-30a/c-5p and DNMT1 Mediates Cisplatin Resistance in Ovarian Cancer Cells. Cell Physiol Biochem 2017;41:973-986.

5 Li C, Ding H, Tian J, Wu L, Wang Y, Xing Y, Chen M: Forkhead Box Protein C2 Promotes EpithelialMesenchymal Transition, Migration and Invasion in Cisplatin-Resistant Human Ovarian Cancer Cell Line (SKOV3/CDDP). Cell Physiol Biochem 2016;39:1098-1110. 


\section{Cellular Physiology Cell Physiol Biochem 2018;49:53-64 \begin{tabular}{l|l|l} 
and Biochemistry Published online: 22 August, 2018 & $\begin{array}{l}\text { @ } 2018 \text { The Author(s). Published by S. Karger AG, Basel } \\
\text { www.karger.com/cpb }\end{array}$ \\
\hline
\end{tabular}}

Hong et al:: Role of YWHAZ in Ovarian Cancer

6 Liu FW, Randall LM, Tewari KS, Bristow RE: Racial disparities and patterns of ovarian cancer surgical care in California. Gynecol Oncol 2014;132:221-226.

7 Lai T, Kessel B, Ahn HJ, Terada KY: Ovarian cancer screening in menopausal females with a family history of breast or ovarian cancer. J Gynecol Oncol 2016;27:e41.

-8 Ying X, Wei K, Lin Z, Cui Y, Ding J, Chen Y, Xu B: MicroRNA-125b Suppresses Ovarian Cancer Progression via Suppression of the Epithelial-Mesenchymal Transition Pathway by Targeting the SET Protein. Cell Physiol Biochem 2016;39:501-510.

9 Li C, Ding H, Tian J, Wu L, Wang Y, Xing Y, Chen M: Forkhead Box Protein C2 (FOXC2) Promotes the Resistance of Human Ovarian Cancer Cells to Cisplatin In vitro and In vivo. Cell Physiol Biochem 2016;39:242-252.

10 Barnett JC, Alvarez Secord A, Cohn DE, Leath CA, 3rd, Myers ER, Havrilesky LJ: Cost effectiveness of alternative strategies for incorporating bevacizumab into the primary treatment of ovarian cancer. Cancer 2013;119:3653-3661.

11 Stark D, Nankivell M, Pujade-Lauraine E, Kristensen G, Elit L, Stockler M, Hilpert F, Cervantes A, Brown J, Lanceley A, Velikova G, Sabate E, Pfisterer J, Carey MS, Beale P, Qian W, Swart AM, Oza A, Perren T: Standard chemotherapy with or without bevacizumab in advanced ovarian cancer: quality-of-life outcomes from the International Collaboration on Ovarian Neoplasms (ICON7) phase 3 randomised trial. Lancet Oncol 2013;14:236-243.

12 Vergote I, Amant F, Kristensen G, Ehlen T, Reed NS, Casado A: Primary surgery or neoadjuvant chemotherapy followed by interval debulking surgery in advanced ovarian cancer. Eur J Cancer 2011;47:S88-92.

-13 Ghosh RD, Ghuwalewala S, Das P, Mandloi S, Alam SK, Chakraborty J, Sarkar S, Chakrabarti S, Panda CK, Roychoudhury S: MicroRNA profiling of cisplatin-resistant oral squamous cell carcinoma cell lines enriched with cancer-stem-cell-like and epithelial-mesenchymal transition-type features. Sci Rep 2016;6:23932.

14 Terao N, Takamatsu S, Minehira T, Sobajima T, Nakayama K, Kamada Y, Miyoshi E: Fucosylation is a common glycosylation type in pancreatic cancer stem cell-like phenotypes. World J Gastroenterol 2015;21:38763887.

15 Patch AM, Christie EL, Etemadmoghadam D, Garsed DW, George J, Fereday S, Nones K, Cowin P, Alsop K, Bailey PJ, Kassahn KS, Newell F, Quinn MC, Kazakoff S, Quek K, Wilhelm-Benartzi C, Curry E, Leong HS, Australian Ovarian Cancer Study G, Hamilton et al.: Whole-genome characterization of chemoresistant ovarian cancer. Nature 2015;521:489-494.

-16 Ruenauver K, Menon R, Svensson MA, Carlsson J, Vogel W, Andren O, Nowak M, Perner S: Prognostic significance of YWHAZ expression in localized prostate cancer. Prostate Cancer Prostatic Dis 2014;17:310314.

17 Li Y, Wang J, Dai X, Zhou Z, Liu J, Zhang Y, Li Y, Hou Y, Pang L, Wang X, Wang C, Hao Z, Zhang Y, Jiang J, Cheng H, Yu D: miR-451 regulates FoxO3 nuclear accumulation through Ywhaz in human colorectal cancer. Am J Transl Res 2015;7:2775-2785.

-18 Watanabe N, Komatsu S, Ichikawa D, Miyamae M, Ohashi T, Okajima W, Kosuga T, Konishi H, Shiozaki A, Fujiwara H, Okamoto K, Tsuda H, Otsuji E: Overexpression of YWHAZ as an independent prognostic factor in adenocarcinoma of the esophago-gastric junction. Am J Cancer Res 2016;6:2729-2736.

19 Liu S, Wu Y, Yang T, Feng C, Jiang H: Coexistence of YWHAZ amplification predicts better prognosis in muscle-invasive bladder cancer with CDKN2A or TP53 loss. Oncotarget 2016;7:34752-34758.

20 Chen CH, Chuang SM, Yang MF, Liao JW, Yu SL, Chen JJ: A novel function of YWHAZ/beta-catenin axis in promoting epithelial-mesenchymal transition and lung cancer metastasis. Mol Cancer Res 2012;10:13191331.

21 Li Y, Zou L, Li Q, Haibe-Kains B, Tian R, Li Y, Desmedt C, Sotiriou C, Szallasi Z, Iglehart JD, Richardson AL, Wang ZC: Amplification of LAPTM4B and YWHAZ contributes to chemotherapy resistance and recurrence of breast cancer. Nat Med 2010;16:214-218.

22 Feng Z, Wen H, Bi R, Ju X, Chen X, Yang W, Wu X: A clinically applicable molecular classification for highgrade serous ovarian cancer based on hormone receptor expression. Sci Rep 2016;6:25408.

-23 Feng Z, Wen H, Bi R, Yang W, Wu X: Prognostic impact of the time interval from primary surgery to intravenous chemotherapy in high grade serous ovarian cancer. Gynecol Oncol 2016;141:466-470. 


\section{Cellular Physiology Cell Physiol Biochem 2018;49:53-64 \begin{tabular}{l|l} 
DOI: 10.1159/000492839 & $\begin{array}{l}\text { O 2018 The Author(s). Published by S. Karger AG, Basel } \\
\text { www.karger.com/cpb }\end{array}$
\end{tabular}}

Hong et al.: Role of YWHAZ in Ovarian Cancer

24 Lo CS, Sanii S, Kroeger DR, Milne K, Talhouk A, Chiu DS, Rahimi K, Shaw PA, Clarke BA, Nelson BH: Neoadjuvant Chemotherapy of Ovarian Cancer Results in Three Patterns of Tumor-Infiltrating Lymphocyte Response with Distinct Implications for Immunotherapy. Clin Cancer Res 2017;23:925-934.

25 Li M, Li H, Liu F, Bi R, Tu X, Chen L, Ye S, Cheng X: Characterization of ovarian clear cell carcinoma using target drug-based molecular biomarkers: implications for personalized cancer therapy. J Ovarian Res 2017;10:9.

-26 Vinje J, Sletten E: NMR spectroscopy of anticancer platinum drugs. Anticancer Agents Med Chem 2007;7:35-54.

-27 Chowanadisai W, Messerli SM, Miller DH, Medina JE, Hamilton JW, Messerli MA, Brodsky AS: Cisplatin Resistant Spheroids Model Clinically Relevant Survival Mechanisms in Ovarian Tumors. PLoS One 2016;11:e0151089.

28 Lu L, Xu X, Zhang B, Zhang R, Ji H, Wang X: Combined PD-1 blockade and GITR triggering induce a potent antitumor immunity in murine cancer models and synergizes with chemotherapeutic drugs. J Transl Med 2014;12:36.

29 Picard M, Matulonis UA, Castells M: Chemotherapy hypersensitivity reactions in ovarian cancer. J Natl Compr Canc Netw 2014;12:389-402.

-30 Casagrande N, Celegato M, Borghese C, Mongiat M, Colombatti A, Aldinucci D: Preclinical activity of the liposomal cisplatin lipoplatin in ovarian cancer. Clin Cancer Res 2014;20:5496-5506.

-31 Lim GE, Piske M, Lulo JE, Ramshaw HS, Lopez AF, Johnson JD: Ywhaz/14-3-3zeta Deletion Improves Glucose Tolerance Through a GLP-1-Dependent Mechanism. Endocrinology 2016;157:2649-2659.

-32 Nishimura Y, Komatsu S, Ichikawa D, Nagata H, Hirajima S, Takeshita H, Kawaguchi T, Arita T, Konishi H, Kashimoto K, Shiozaki A, Fujiwara H, Okamoto K, Tsuda H, Otsuji E: Overexpression of YWHAZ relates to tumor cell proliferation and malignant outcome of gastric carcinoma. Br J Cancer 2013;108:1324-1331.

-33 Lin M, Morrison CD, Jones S, Mohamed N, Bacher J, Plass C: Copy number gain and oncogenic activity of YWHAZ/14-3-3zeta in head and neck squamous cell carcinoma. Int J Cancer 2009;125:603-611. 